\title{
6. Organisational Alignment: How Project Management Helps
}

\section{Abul Rizvi, Department of Immigration and Multicultural Affairs}

As many of you will know, in February 2005 the Minister for Immigration and Multicultural Affairs, Senator Amanda Vanstone commissioned Mr Mick Palmer to investigate the circumstances of the immigration detention of Ms Cornelia Rau.

During the process of this investigation, another report, by Mr Neil Comrie, into the Circumstances of the Vivian Alvarez Matter, was also commissioned.

Mr Palmer delivered his report in July 2005 and Mr Comrie in October. These reports were highly critical of the Department and made a number of recommendations - most of which addressed shortcomings they saw in DIMA's culture and organisational practices.

Both reports found DIMA wanting on a number of fronts and have lessons perhaps for many government agencies about:

- communication;

- $\quad$ structure \& governance;

- accountability;

- contract management;

- case management;

- IT Systems;

- identity issues;

- quality decision making;

- leadership; and

- training.

Late last year the Government accepted the broad thrust of the findings and recommendations in the Palmer Report and the Comrie Report. This kick-started a major organisational change process.

The change agenda we are undertaking is substantial. It is across the whole department, and has to be carried out against a background of keeping the business going - and what a business it is.

In last 12 months DIMIA has

- $\quad$ responded to more than 1.6 million telephone inquires;

- facilitated the arrival of more than 5.7 million temporary entrants; 
- granted visas to over 12,000 migrants. Granted humanitarian visas and then settled more than 11,500 refugees and people in humanitarian need;

- heard around 4,800 applications for AAT or judicial review of Departmental or tribunal decisions; and

- been mentioned at least 31,750 times on the TV or radio and over 37,800 in newspapers.

Everyday, DIMA staff have to make decisions which can dramatically affect peoples' lives. We recognise that this is a big workload on which to place such a substantial change agenda. We are doing this in the glare of public scrutiny and in the face of competing (and often conflicting) expectations about what it is that DIMA should do.

DIMA business is complex and diverse. We range from working across government on counter-terrorism and border security, playing our part in the international response to humanitarian crises (in the short and medium term), promoting the benefits of cultural diversity in the Australian community, helping new migrants become active and productive members of that community and contributing to economic growth by facilitating the entry of people to fill skilled positions or who come as tourists or as students.

We deliver services on behalf of a number of other agencies - health, education, industry, security and community services. These other agencies require different approaches and have different objectives and we have to balance each one against the other.

The Australian community also has different expectations of our work. Business wants easy and seamless access to skills and a competitive environment for attracting tourists and students. Families want to be able to bring their loved ones to Australia. Some sectors of the community think we should do more on the humanitarian front, while other sectors want to feel assured that we administer a strong immigration policy with inbuilt safeguards against introduced disease, abuse and possible criminal activity.

Measuring the success of the changes in the light of these competing objectives will not be easy.

\section{So, how do we go about doing this?}

To respond properly to the Palmer and Comrie reports, and to meet the expectations of the Government, the Parliament and the wider community, we have identified that we must do three things:

- become a more open and accountable organisation;

- deal more fairly and reasonably (and lawfully) with clients; and

- have staff that are well trained and supported. 


\section{Being more open and accountable}

Since the Palmer and Comrie reports, the Minister has twice directly and personally addressed all DIMA staff on the Government's expectations of the reform agenda. She continues to encourage staff to share ideas for change and improvement. The Secretary has continued his practice of communicating twice weekly with all staff in the Department and delivering keynote addresses, updating staff on current issues and achievements and seeking their input and ideas.

The Senior Executive has travelled to all of our capital city offices in Australia and a number of our overseas posts to discuss the reform agenda and hear first hand the impact it is having on our state and territory and overseas operations. We have continued to engage with our clients, critics and other organisations, particularly those who have a role in scrutinising the activities of the Department.

We have very constructive relationships with the Commonwealth Ombudsman's Office and the Office of the Federal Privacy Commissioner and their feedback is highly valued. A privacy training strategy has been developed and training has commenced. The restructure of our National Office is complete and new and stronger governance arrangements are in place.

A whole range of appointments have been made to Senior Executive Service and State Director positions. The new Values and Standards Committee is up and running. With its three external members (from the Ombudsman's Office. The Australian Public Service Commission and the community), it is well placed to ensure that the Department is meeting community expectations. An expanded Audit and Evaluation Committee, with an external chair, is providing rigorous oversight of the enhanced internal audit program.

For the first time in many years, there has been a comprehensive staff survey to assess the views of staff and to provide a benchmark for monitoring change. The report will be available shortly and the Department's executive will be taking a strong personal interest in developing the responses to staff ideas and concerns.

\section{Being more fair and reasonable with clients}

Improving client service must be a key focus of our efforts. Client Satisfaction surveys and Values Creation Workshops, where DIMA staff must actively listen to the views and concerns of clients, will be conducted in the early part of this year. This will allow us to better understand the differences between client groups and their needs and will allow us to respond to systemic concerns that clients raise.

DIMA's National Office in Canberra is a long way from the service counters where we interact with our clients. We have therefore also asked all of the senior 
executives in DIMA to spend some time in operational or service delivery parts of the Department in the first half of this year to get first-hand experience in client service.

The draft Client Service Charter released last year for public comment is being finalised at the moment to take account of the largely positive feedback. It will set out clearly the expectations for both clients and DIMA staff. Better arrangements are being put in place for handling client feedback and providing clients with choice about how they connect with the Department.

Every month the Secretary recognises a member of staff or team through the Secretary's Award for Service Excellence (ASCE) on the basis of positive client feedback.

We have further built on improvements made last year to health service delivery for immigration detainees, in particular at Baxter with other centres to progressively follow over coming months.

All detainees are screened for mental health problems using two internationally recognised screening tools on admission and they are routinely and regularly screened after that. Mental health plans are developed for any detainee who screens positive. We are currently finalising the membership of the Detention Health Advisory Group, which will provide expert professional health advice on health service standards and research projects to improve health outcomes for people detained.

Physical improvements at Baxter and other immigration detention centres have been made, well beyond the recommendations made in the Palmer Report. The Baxter Plan, launched by the Minister in September 2005, included development of the Interim Visitor Processing Centre, which opened in December, and sporting facilities. Self-catering options have improved and further design options to open up the closed compounds, develop a new primary health care facility and a new central cafeteria have been developed.

Considerable progress has been made in developing a new, holistic, case management framework for the case management of clients with exceptional circumstances. In conjunction with case management, DIMA is developing a 'community care' pilot in Sydney and Melbourne to trial and evaluate a model where case management is supported by access to additional community services to vulnerable clients.

Appropriately skilled and qualified case management staff have been recruited, trained and are now working in our Sydney and Melbourne Offices. Our compliance activities have been properly criticised and will continue to be criticised in those cases which come to light where people have been improperly determined to be unlawful and detained. 
Clearly, DIMA officers exercise extraordinary powers and we have to be extraordinarily careful in our decision-making where the outcome can be the deprivation of liberty. We are making committed efforts to ensure decisions to detain are only made where there is no realistic alternative, and that they are subject to ongoing review. We will continue to place a strong focus on training for staff in these operational roles, and in ensuring there are strong accountability mechanisms in place.

This is especially the case where we are faced with people who are not easily identified, either because they do not wish to cooperate, have mental health issues or for other reasons. These difficulties do not release us from our obligation to make each decision on the basis of law and the facts and to review those decisions regularly.

\section{Having well trained and supported staff}

Enhanced training for staff is the centrepiece of the reform agenda for DIMA. Plans for the new College of Immigration, Border Security and Compliance are on track to commence training in mid-2006.

In the meantime, specialist technical training is being provided, addressing areas such as making decisions on the basis of 'reasonable suspicion', using all available methods to identify people, issuing search warrants and case management. These courses will ultimately become part of the College curriculum.

Enhanced training in ICSE, DIMA's main processing system, was rolled-out in November and December last year and further modules in this e-learning program are being delivered in 2006.

Leadership, values, standards and management skills were also areas of concern identified by both Palmer and Comrie and a new National Training Manager was appointed in early December to develop and lead the new department-wide training programs in these areas.

The Executive Leadership program commenced delivery in September last year. All DIMA executive level staff will undertake this course. A development program for lower-level managers, a Fundamentals of Leaderships Program and enhanced induction training are all being delivered to staff.

The significant systems issues identified by Palmer and Comrie are being addressed. Independent reviews of DIMA's business information needs, systems governance, the IT platform and records management arrangements have been finalised and their recommendations are currently being considered. Pilot projects to better support DIMA staff in the field have also been completed, including using Blackberry technology to connect remotely to the ICSE system and trialling a field office. These pilots have shown acceptable results and will be considered for further development. 
If implementation is to be driven hard it, is important that there be clarity of purpose, powers and relationships and transparency of authority, accountability and disclosure. Project and program management techniques help do this. At one level project management is a discipline, but at another level it is just common sense. It is about setting objectives and planning how to meet them

We have recognised this and have incorporated in our new structure a Program Services Office (in the Strategic Policy Group) to help business owners develop plans and to monitor progress on the implementation of the Palmer Projects and other key initiatives.

To ensure that DIMA staff, including those in the Senior Executive Service understand the principles of project management, a series of information sessions and one and two day workshops are underway. Response to project training has exceeded our expectations and regular project management training will be part of the long term training strategy.

Regular reports are fed up to the Executive Management Committee and to the Cabinet Implementation Unit (CIU) of the Department of the Prime Minister and Cabinet.

We are also required to report to the Minister on progress on a regular basis and we are required to report progress to Parliament in September 2006.

We could not do this successfully and honestly without a program management approach.

Our success in achieving change will be measured by improvements in the confidence the Department is able to inspire in the broader community, including recognition of the benefits delivered by a well managed and administered immigration program.

Success will be reflected in the fact that our decisions are fair and reasonable, that implementation of policy is open and there are clear lines of accountability through the DIMA executive, to the Minister and Government and to the Parliament and the broader community.

Measuring our success must take place on a couple of different planes. Our overall success will be measured through things such as:

- the community's acceptance of the level and nature of our immigration program;

- the recognition of the net economic benefits delivered by a well managed immigration program, including how it assists in Australia's economic growth through improved productivity and export performance;

- the settlement success of migrants; and

- our contribution to border security by preventing people with major health or criminal issues from entering Australia. 
The success of the Palmer Plus program of work can be measured by:

- positive feedback from our clients (even if they do not like the decision, do they feel that they have been treated fairly and reasonably throughout the process?);

- easier and faster access to information by the staff and the public;

- faster resolution of identity issues;

- reduction in visa overstayers through improved education of both visa holders and employers;

- improved processing times for complex cases;

- positive audit and Ombudsman reports; and

- feedback from staff on whether the changes are making it easier for them to do their jobs in a fair and reasonable way.

Change does not come easily to large organisations - it takes time and commitment. And while under no illusions about the scale of the task, we are confident that we have the capacity to deliver on the change agenda. We shall be judged on what we have achieved. 